\title{
Composition control of pulsed laser deposited copper (I) chalcogenide thin films via plasma/Ar interactions
}

\author{
Jikun Chen ${ }^{1 \dagger}$, Yanhong $\mathrm{Lv}^{1,2,3 \dagger}$, Max Döbeli ${ }^{4}$, Yulong $\mathrm{Li}^{1,2,3}$, Xun Shi ${ }^{1,2^{*}}$ and Lidong Chen ${ }^{1,2}$
}

\begin{abstract}
We present how the applied Ar background pressure correlates to the cation and anion composition of $\mathrm{Cu}(\mathrm{I})$ chalcogenide thin films grown by pulsed laser deposition (PLD). The as-grown films produced at $\sim 10^{-2}$ mbar $p$ Ar show a more pronounced deficiency in lighter composition, as compared with using quasi-vacuum or $\sim 10^{-1}$ mbar. The thermoelectric performance of the as-grown $\mathrm{Cu}_{2} \mathrm{Se}$ varies consistently with the respective changes in $\mathrm{Cu} / \mathrm{Se}$ ratio vs. $p$ Ar. The optimum thermoelectric performance of $\mathrm{Cu}_{2} \mathrm{Se}$ is achieved by growing in vacuum or quasi-vacuum, where dense and even thin film morphology is obtained while the cation/anion composition is more congruent than at higher $p$ Ar.
\end{abstract}

How to accurately control the thin film composition is one of the most important issues when growing thin films with a complex composition [1-5]. Pulsed laser deposition (PLD) is known as an effective approach to achieve the congruency in composition between the target and the as-grown thin film. Unlike the other deposition approaches such as molecular beam epitaxy (MBE), atomic layer deposition (ALD) or magnetron sputtering, the transfer of material stoichiometry in PLD is achieved by a laser-induced plasma plume expanding in background gas pressures variable within a broad range from $10^{-7}$ to 1 mbar $[4,5]$. However, in contrast to what is expected, for many practical depositions, a congruent thin film growth is not always easily achievable when using PLD. An inconsistency in composition between target and the as-grown thin films may be caused during the plasma generation, propagation and deposition processes, which can be summarized from both intrinsic and extrinsic aspects. Intrinsic reasons include an incongruent laser ablation [6-8], the preference in background scattering [9-11], diversity in angular distribution of the plasma elements [12], and preferential resputtering of lighter constituents [13]. In addition, extrinsic reasons, such as target degradation, inhomogeneity of energy density in the laser spot, or incorrect alignment of the substrate in respect to the laser spot position [14], can also cause an incongruent thin film growth. The previous report in Ref. [9] shows that a congruent transfer of the cation element can be achieved when growing $\mathrm{La}_{0.6} \mathrm{Sr}_{0.4} \mathrm{MnO}_{3}$ oxide thin films at $10^{-1} \mathrm{mbar} p \mathrm{O}_{2}$, at which pressure the plasma plume propagates as a shockwave. The formation of a shockwave front strongly confines the spatial distribution of the plasma species with various atomic weights, and maintains a congruent transfer of the target elements [9]. Meanwhile, a high anion (oxygen) composition is easily replenished via chemical reactions with the oxygen background. However, the situation is different when growing metal-chalcogenide compounds such as $\mathrm{Bi}_{2} \mathrm{Se}_{x} \mathrm{Te}_{3-x}, \mathrm{Bi}_{2-x} \mathrm{Sb}_{x} \mathrm{Te}_{3}, \mathrm{Cu}_{2} \mathrm{~S}, \mathrm{Cu}_{2} \mathrm{Se}$, $\mathrm{CdTe}$ or CuInGaSe (CIGS) by PLD in noble gas background, such as argon (Ar) [15-19]. For these depositions, it is not possible to replenish the anion composition via chemical reactions with the background molecules. Therefore, congruent transferes of cation and anion components are both important.

In this letter, we address how the applied Ar background gas pressure correlates to the composition of $\mathrm{Cu}(\mathrm{I})$ chalcogenide thin films grown by PLD. The compositions of the as-grown thin films were measured by Rutherford backscattering (RBS). Among the copper (I) chalcogenide family, $\mathrm{Cu}_{2} \mathrm{Se}$ recently received extensive attention for potential thermoelectric or photovoltaic energy conversion applications $[20,21]$. The electrical transportation performance of metal-chalcogenide compounds has been observed to heavily depend on the ratio between the cation and chalcogen composition [20,21]. Taking the growth of the $\mathrm{Cu}_{2} \mathrm{Se}$ thermoelectric compound as a typical example, we establish the correlation among the applied Ar pressure for deposition, thin film composition and thin film thermoelectric performances. The strategy towards how to utilize the proper background scattering to control the thin film composition is suggested.

\footnotetext{
${ }^{1}$ State Key Laboratory of High Performance Ceramics and Superfine Microstructure, Shanghai Institute of Ceramics, Chinese Academy of Sciences, Shanghai 200050, China

${ }^{2}$ CAS Key Laboratory of Materials for Energy Conversion, Shanghai Institute of Ceramics, Chinese Academy of Sciences, Shanghai 200050, China ${ }^{3}$ University of Chinese Academy of Sciences, Beijing 100049, China

${ }^{4}$ Laboratory of Ion Beam Physics, ETH Zurich, CH-8093 Zurich, Switzerland

${ }^{\dagger}$ The first two authors contributed equally to this work. Jikun Chen is currently at School of Engineering and Applied Science, Harvard University.

Corresponding author (email: xshi@mail.sic.ac.cn)
} 
In order to prepare the $\mathrm{Cu}(\mathrm{I})$ chalcoginide thin films, the laser beam profile ( $\mathrm{KrF}$ excimer laser $\lambda=248 \mathrm{~nm}$ ) was imaged by a rectangular aperture onto the target material inside a vacuum chamber with a base pressure lower than $10^{-6}$ mbar. Ar was used as background gas and was kept at a constant partial pressure from $\sim 5 \times 10^{-3}$ to $1 \times 10^{-1}$ mbar. The $\mathrm{Cu}_{2} \mathrm{Se}$ was grown on (001) $\mathrm{Si}$ at room temperature or $(\mathrm{La}, \mathrm{Sr})(\mathrm{Al}, \mathrm{Ta}) \mathrm{O}_{3}$ (LAST) substrates at $150^{\circ} \mathrm{C}$ in vacuum or $p A r$ at a laser ablation fluence $(F)$ of $5 \mathrm{~J} \mathrm{~cm}^{-2}$ and target to substrate distance $d_{\mathrm{T}-\mathrm{S}}=5 \mathrm{~cm} . \mathrm{Cu}_{2} \mathrm{~S}$ and $\mathrm{Cu}_{2}$ Te were grown on (001) $\mathrm{Si}$ at room temperature in vacuum or $p$ Ar using $F=5 \mathrm{~J} \mathrm{~cm}^{-2}$ and $d_{\mathrm{T}-\mathrm{S}}=5 \mathrm{~cm}$. The film composition was measured by RBS performed using a $2 \mathrm{MeV}^{4} \mathrm{He}$ beam and a silicon PIN diode detector at $\theta=168^{\circ}$. The collected RBS data were simulated using the RUMP software [9]. Scanning electron microscopy (SEM) analysis was performed on a JSM-6360LV scanning electron microscope. Electrical transport properties of the films were measured using a homemade thermopower and electrical conductivity measurement system, which is refitted based on the thermal expansion equipment (Netzsch DIL 402C) [21], and the error of which is around $10 \%$ for the measurement of thin films.

When using Ar background pressures, both cation and anion components are solely provided by the target material. This is in contrast to the growth of oxide material under oxygen pressures, where the oxygen anion composition can be easily replenished by background interactions or post annealing [2-5]. Fig. 1 shows the composition of the as-grown $\mathrm{Cu}_{2} \mathrm{~S}_{x}, \mathrm{Cu}_{2} \mathrm{Se}_{y}$ and $\mathrm{Cu}_{2} \mathrm{Te}_{z}$ vs. pAr on silicon

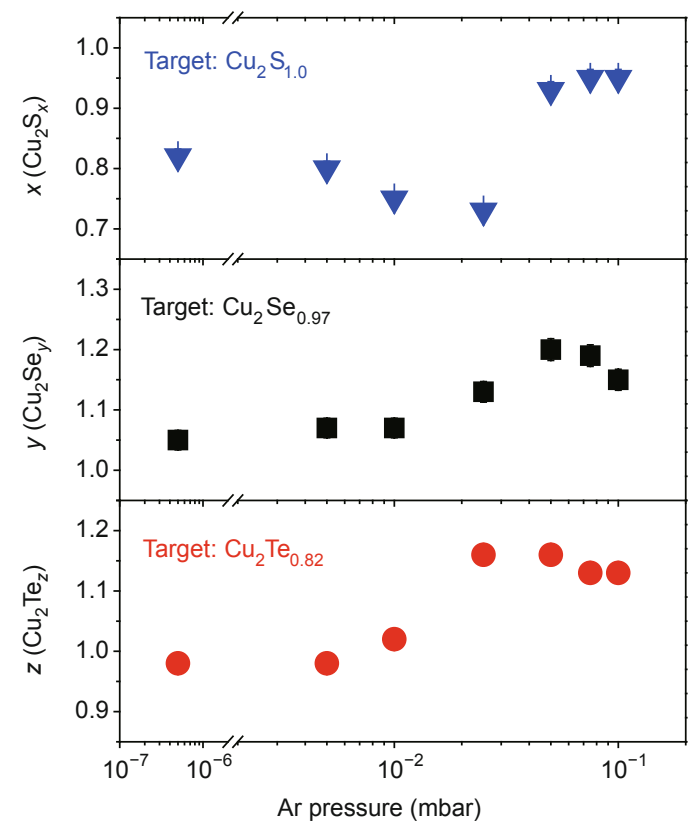

Figure $1 \mathrm{~S}, \mathrm{Se}$ and $\mathrm{Te}$ composition of $\mathrm{Cu}_{2} \mathrm{~S}_{x}, \mathrm{Cu}_{2} \mathrm{Se}_{y}$ or $\mathrm{Cu}_{2} \mathrm{Te}_{z}$ thin films deposited on (001) Si substrates at room temperature as a function of the Ar background pressure using $5 \mathrm{~J} \mathrm{~cm}^{-2}$ ablation fluence. substrates at room temperature. The vacuum is around the high $10^{-7}$ mbar range, which is approximately represented in Fig. 1 by a number of $5 \times 10^{-7}$. For a better comparison, the copper composition is used as the reference (set as 2), and the respective chalcogen composition is plotted accordingly. In Fig. 2, the deviations of chalcogen composition in $\mathrm{Cu}_{2} \mathrm{~S}_{x}, \mathrm{Cu}_{2} \mathrm{Se}_{y}, \mathrm{Cu}_{2} \mathrm{Te}_{z}$ thin films as compared to the target composition $\left(\mathrm{Cu}_{2} \mathrm{~S}_{1}, \mathrm{Cu}_{2} \mathrm{Se}_{0.97}\right.$ and $\left.\mathrm{Cu}_{2} \mathrm{Te}_{0.82}\right)$ are further compared. Shown deviations (in percentages) are calculated as $(x-1) / 1,(y-0.97) / 0.97$ and $(z-0.82) / 0.82$ for $\mathrm{Cu}_{2} \mathrm{~S}_{x}, \mathrm{Cu}_{2} \mathrm{Se}_{y}$ and $\mathrm{Cu}_{2} \mathrm{Te}_{z}$, respectively. The atomic weights of $\mathrm{Cu}, \mathrm{S}$, Se and Te are 63.5, 32, 80 and 127.6, respectively. As a result, the as-grown $\mathrm{Cu}_{2} \mathrm{~S}_{x}$ thin films in general show $S$ deficiency compared with the target composition, while a deficiency in $\mathrm{Cu}$ has been generally observed for the asgrown $\mathrm{Cu}_{2} \mathrm{Se}_{y}$ and $\mathrm{Cu}_{2} \mathrm{Te}_{z}$ thin films. This result is in agreement with the previous understanding that a deficiency in lighter components is usually observed when preparing thin films by PLD [2]. Nevertheless, it is interesting to note that the most significant deficiency in lighter constituents was observed when using a $p$ Ar of $\sim 10^{-2}$ mbar. Similar effects have been also observed in previous reports for the cation compositions of the as-grown $\mathrm{La}_{x} \mathrm{Sr}_{1-x} \mathrm{MnO}_{3}$ [9] or $\mathrm{Ca}_{3} \mathrm{Co}_{4} \mathrm{O}_{9}[10]$ vs. $p \mathrm{O}_{2}$.

By using fixed laser ablation conditions for the current experiment, the variation in thin film composition $v s$. $p \mathrm{Ar}$ is expected to be associated to the following two effects: 1 ) background scattering of the plasma plume; and 2) resputtering of the thin film components by the arriving plasma species. The collision mean free path $l$ between plasma species and background molecules is determined by $l=k T /$ $\left[P \pi\left(R_{1}+R_{2}\right)^{2}\right]$, where $k$ is the Boltzmann constant, $T$ is the absolute temperature, $P$ is the background pressure, while $R_{1}$ and $R_{2}$ represent the atomic radii of the plasma species and background molecule, respectively. It is worth to note

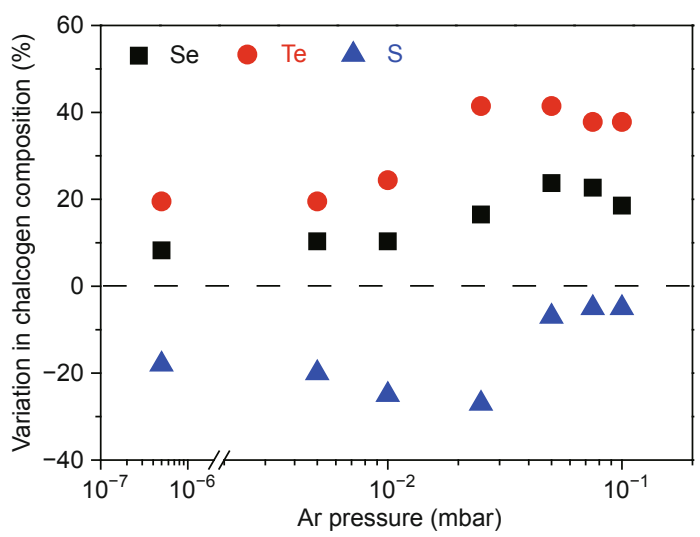

Figure 2 Deviation in the chalcogen composition of the as-grown $\mathrm{Cu}(\mathrm{I})$ chalcogenide thin films as compared with the target composition $\left(\mathrm{Cu}_{2} \mathrm{~S}_{1}\right.$, $\mathrm{Cu}_{2} \mathrm{Se}_{0.97}$ and $\left.\mathrm{Cu}_{2} \mathrm{Te}_{0.82}\right)$. Shown percentages are calculated as $(x-1) / 1$, $(y-0.97) / 0.97,(z-0.82) / 0.82$ for $\mathrm{Cu}_{2} \mathrm{~S}_{x}, \mathrm{Cu}_{2} \mathrm{Se}_{y}$ and $\mathrm{Cu}_{2} \mathrm{Te}_{z}$, respectively. 
that $l$ varies inverse-proportionally to $P$.

In vacuum or quasi-vacuum, $l$ is much larger than the propagation distance of the plasma plume. Therefore, the plasma plume is not effectively scatterred by the background molecules and influences its composition. However, since the free expanding plasma species possess a large kinetic energy up to hundreds of $\mathrm{eV}$ [10], it causes a pronounced resputtering of the thin film components with a preference in the lighter constituents. This understanding is supported by the observed S deficiency in the as-grown $\mathrm{Cu}_{2} \mathrm{~S}_{x}$ as well as the $\mathrm{Cu}$ deficiency when growing $\mathrm{Cu}_{2} \mathrm{Se}_{y}$ or $\mathrm{Cu}_{2} \mathrm{Te}_{z}$ thin films. A further comparison indicates a smaller deficiency of the lighter component when growing $\mathrm{Cu}_{2} \mathrm{Se}_{y}$ in vacuum (Cu deficiency: $8.3 \%$ ), as compared with growing $\mathrm{Cu}_{2} \mathrm{Te}_{z}$ (Cu deficiency 19.5\%) and $\mathrm{Cu}_{2} \mathrm{~S}_{x}(\mathrm{~S}$ deficiency: 18\%). This can be explained by the larger difference in atomic weights between cation and anion atoms for $\mathrm{Cu}_{2} \mathrm{~S}$ and $\mathrm{Cu}_{2} \mathrm{Te}$, as compared with $\mathrm{Cu}_{2} \mathrm{Se}$. In addition, the cohesive energy between $\mathrm{Cu}$ and $\mathrm{Se}\left(293 \mathrm{~kJ} \mathrm{~mol}^{-1}\right)$ is larger than that between $\mathrm{Cu}$ and $\mathrm{S}\left(285 \mathrm{~kJ} \mathrm{~mol}^{-1}\right)$ or $\mathrm{Cu}$ and $\mathrm{Te}\left(176 \mathrm{~kJ} \mathrm{~mol}^{-1}\right)$ [22]. This may be another reason for the larger diversity between target and thin film observed when growing $\mathrm{Cu}_{2} \mathrm{~S}$ or $\mathrm{Cu}_{2} \mathrm{Te}$ as compared with $\mathrm{Cu}_{2} \mathrm{Se}$ [23].

When increasing the $p$ Ar to $\sim 10^{-2} \mathrm{mbar}, l$ is reduced to a magnitude similar to the propagation distance of the plasma plume. Therefore, effective interactions between the plasma species and the Ar background molecules already start. On the one side, collisions with the Ar molecules reduce the kinetic energy of the plasma species and therefore resputtering of the thin film components is less pronounced as compared with the vacuum situation. On the other side, however, the lighter plasma species is more easily scattered by interactions with the background molecules $[9,10]$. Despite the competition between the two opposite mechanisms, the most significant deficiency is observed in the lighter constituent.

By further elevating the background pressure towards $\sim 10^{-1}$ mbar, $l$ is about ten times smaller than the plasma propagation distance. The intensive collisions with the Ar molecules change the plasma propagation from a free expansion in vacuum or quasi-vacuum $\left(10^{-3}\right.$ mbar or lower) to the described shockwave propagation $\left(\sim 10^{-1} \mathrm{mbar}\right)$ $[5,9,24-26]$. As a result, the plasma species is more effectively stopped, compressed together with the background molecules, forming a relatively dense shockwave front [2427]. The shockwave front largely confines the spatial distribution of plasma species despite the difference in their atomic weights, which results in a more congruent transfer of the target element as compared with the deposition at $\sim 10^{-2}$ mbar [9]. At the same time, the kinetic energy of the plasma species is significantly reduced to several eV [10] which is insufficient to cause a pronounced resputtering of the thin film constituents. As a result, a larger content of the lighter component is observed when growing all three types of $\mathrm{Cu}(\mathrm{I})$ chalchogenide compounds using $\sim 10^{-1} \mathrm{mbar}$ pAr as compared with the one using $\sim 10^{-2}$ mbar pAr. A further comparison among the growth of $\mathrm{Cu}_{2} \mathrm{~S}, \mathrm{Cu}_{2} \mathrm{Se}$ and $\mathrm{Cu}_{2}$ Te thin films at $10^{-1}$ mbar $p$ Ar indicates a more congruent growth for $\mathrm{Cu}_{2} \mathrm{~S}$ as compared to $\mathrm{Cu}_{2} \mathrm{Se}$ or $\mathrm{Cu}_{2} \mathrm{Te}$. This is in contrast to the situation of growing in vacuum and may be associated to a less effective spatial confinement of the heavier Se or Te compared with the lighter S, when providing a constant $p$ Ar in the $10^{-1}$ mbar range.

Although thin films grown at both quasi-vacuum and $\sim 10^{-1}$ mbar $p$ Ar possess a more congruent composition as compared to the one grown at $\sim 10^{-2}$ mbar $p$ Ar, a significant difference in their morphology has been observed. Fig. 3 shows both in-plane and cross-plane morphology of the as-grown $\mathrm{Cu}_{2} \mathrm{Se}$ thin films on LAST substrates at $150^{\circ} \mathrm{C}$ in different $p$ Ar. It is worthwhile to note that thin films grown in vacuum possess a smooth surface with uniform thickness, while a porous morphology with uneven thickness is observed for films grown at high $p$ Ar. Similar observations have also been made in previous reports $[28,29]$ and may be associated with the reduced kinetic energy of the arriving plasma due to more pronounced background scattering in higher $p$ Ar. As compared to the growth of oxide thin films, this effect is expected to be more pronounced for the current experiment due to the much lower substrate temperature applied in order to prevent the evaporation of the chalcogen composition. The low substrate temperature impedes the migration of the arriving plasma species at the substrate. This makes the thin film morphology more influenced by the plasma properties, which is determined by the background scatterings.

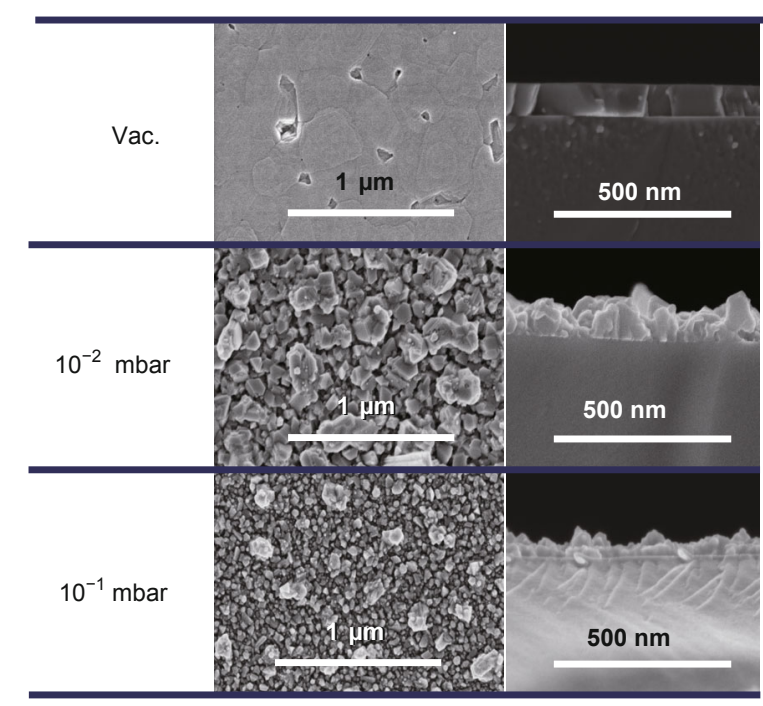

Figure 3 In-plane (left) and cross-section (right) morphology of the asgrown $\mathrm{Cu}_{2} \mathrm{Se}_{y}$ films on LAST in vacuum (Vac.) and Ar pressures. 
The variation in composition and morphology further influences the electrical transportation performances of the as-grown thin films. The carrier concentration, resistivity $(r)$ and Seebeck coefficient $(S)$ of the $\mathrm{Cu}_{2}$ Se has been reported to be rather sensitive to the $\mathrm{Cu} / \mathrm{Se}$ ratio $[20,21]$. Fig. 4 shows the $r, S$ and power factor $(\mathrm{PF})$ of the as-grown $\mathrm{Cu}_{2} \mathrm{Se}_{x}$ films vs. pAr measured at room temperature. Increasing $p$ Ar from vacuum to $\sim 10^{-2}$ mbar using a fixed ablation fluence results in a reduction of $r$ as well as $S$ of $\mathrm{Cu}_{2} \mathrm{Se}_{x}$, implying an increased carrier concentration due to the enhanced copper deficiency [20]. This observation is in agreement with the changes in thin film composition shown in Figs 1 and 2, i.e., that an increase of $p$ Ar from vacuum to $10^{-2}$ mbar reduces the $\mathrm{Cu} / \mathrm{Se}$ ratio. By further raising $p$ Ar from $10^{-2}$ mbar to $10^{-1} \mathrm{mbar}$, a slight increase is observed in $S$. This is caused by a more congruent element transfer in the $10^{-1}$ mbar pressure range that reduces copper deficiency (see Fig. 1), and hence, the carrier concentration [20]. The resistivity of the $\mathrm{Cu}_{2} \mathrm{Se}$ film grown at high $p \mathrm{Ar}$ is relatively large due to the larger roughness as shown in Fig. 2. As a result of the opposite trend of the thin film conductivity $(1 / r)$ and Seebeck coefficient, the maximum power factor is achieved for vacuum growth (with maximum $S$ ) or $5 \times 10^{-3}$ mbar pressure (with lowest resistance). We can see that the optimum deposition of $\mathrm{Cu}_{2} \mathrm{Se}$ is observed when using vacuum or quasi-vacuum, under which conditions a more congruent transfer of $\mathrm{Cu} / \mathrm{Se}$ composition, uniform morphology and better thermoelectric performance are achieved. This is in contrast to the depositions of most oxide thin films, where an oxygen containing background at $10^{-1}$ mbar range is usually used $[2,3,5,9]$.

In summary, we present how the applied Ar background pressure and the respective background scatterings influence the cation and anion compositions when growing $\mathrm{Cu}(\mathrm{I})$ chalcogenide thin films by PLD. Thin films grown at $\sim 10^{-2}$ mbar $p$ Ar show the most pronounced deficiency in the lighter component, as compared with the films

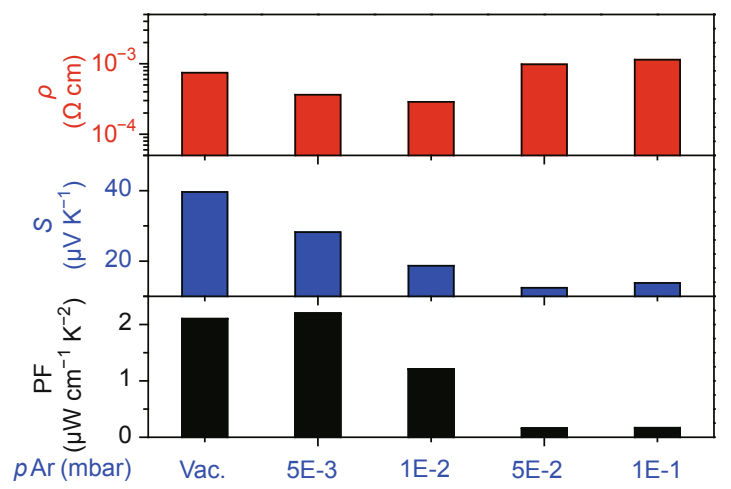

Figure 4 Resistivity, Seebeck coefficient and power factor of the as-grown $\mathrm{Cu}_{2} \mathrm{Se}_{y}$ films on LAST in vacuum as well as using various Ar pressures grown under quasi-vacuum condition or $\sim 10^{-1}$ mbar. This indicates that a most preferential scattering of the plasma species by the background molecules occurs at a condition where the collision mean free path between plasma and background molecules is similar to the propagation distance of the plasma plume. In that case, effective background scatterings already start. However, the interactions with the background molecules are not sufficient to completely transform the plasma propagation into a shockwave, which strongly confines the spatial distribution of the plasma species despite the difference in their atomic weights. The thermoelectric performance of the as-grown $\mathrm{Cu}_{2} \mathrm{Se}$ thin films varies consistently with the respective changes in $\mathrm{Cu} / \mathrm{Se}$ ratio vs. pAr. The optimum thermoelectric performance is achieved when growing $\mathrm{Cu}_{2} \mathrm{Se}$ in vacuum or quasi-vacuum, where a more congruent $\mathrm{Cu} / \mathrm{Se}$ ratio is achieved while the thin film morphology is dense and even. This is in contrast to the pressure range used for a congruent growth of oxide material at the low $10^{-1}$ mbar. The present investigation provides a better understanding of how to select a proper background gas condition in order to better control the cation and anion composition when growing metal-chalcogenide thin films by PLD.

Received 26 January 2015; accepted 16 March 2015; published online 26 March 2015

1 Lowndes DH, Geohegan DB, Piretzky AA, et al. Synthesis of novel thin-film materials by pulsed laser deposition. Science, 1996, 273: 898-903

2 Willmott PR, Huber JR. Pulsed laser vaporization and deposition. Rev Mod Phys, 2000, 72: 315-328

3 Song JH, Susaki T, Hwang HY. Enhanced thermodynamic stability of epitaxial oxide thin films. Adv Mater, 2008, 20: 2528-2532

4 Chambers SA. Epitaxial growth and properties of doped transition metal and complex oxide films. Adv Mater, 2010, 22: 219-248

5 Chen J. Analysis of Laser-Induced Plasmas Utilizing ${ }^{18} \mathrm{O}_{2}$ as Oxygen Tracer. Doctoral Dissertation. Zurich: ETH Zurich, 2014

6 Ohnishi T, Lippmaa M, Yamamoto T, et al. Improved stoichiometry and misfit control in perovskite thin film formation at a critical fluence by pulsed laser deposition. Appl Phys Lett, 2005, 87: 241919

7 Breckenfeld E, Bronn N, Karthik J, et al. Effect of growth induced (non) stoichiometry on interfacial conductance in $\mathrm{LaAlO}_{3} / \mathrm{SrTiO}_{3}$. Phys Rev Lett, 2013, 110: 196804

8 Breckenfeld E, Wilson R, Karthik J, et al. Effect of growth induced (non)stoichiometry on the structure, dielectric response, and thermal conductivity of $\mathrm{SrTiO}_{3}$ thin films. Chem Mater, 2012, 24: 331-337

9 Chen J, Döbeli M, Stender D, et al. Plasma interactions determine the composition in pulsed laser deposited thin films. Appl Phys Lett, 2014, 105: 114104

10 Chen J, Palla-Papavlu A, Li Y, et al. Laser deposition and directwriting of thermoelectric misfit cobaltite thin films, Appl Phys Lett, 2014, 104: 231907

11 Liu GZ, Lei QY, Xi XX. Stoichiometry of $\mathrm{SrTiO}_{3}$ films grown by pulsed laser deposition. Appl Phys Lett, 2012, 100: 202902

12 Droubay TC, Qiao L, Kaspar TC, et al. Nonstoichiometric material transfer in the pulsed laser deposition of $\mathrm{LaAlO}_{3}$. Appl Phys Lett, 2010, 97: 124105 
13 Fähler S, Sturm K, Krebs HU. Resputtering during the growth of pulsed-laser-deposited metallic films in vacuum and in an ambient gas. Appl Phys Lett, 1999, 75: 3766.

$14 \mathrm{Xu} \mathrm{C}$, Wicklein S, Sambri A, et al. Impact of the interplay between nonstoichiometry and kinetic energy of the plume species on the growth mode of $\mathrm{SrTiO}_{3}$ thin films. J Phys D Appl Phys, 2014, 47: 034009

15 Makala RS, Jagannadham K, Sales BC. Pulsed laser deposition of $\mathrm{Bi}_{2} \mathrm{Te}_{3}$-based thermoelectric thin films. J Appl Phys, 2003, 94: $3907-$ 3918

16 Li Bassi AL, Bailini A, Casari CS, et al. Thermoelectric properties of Bi-Te films with controlled structure and morphology. J Appl Phys, 2009, 105: 124307

17 Li B, Liu J, Xu G, et al. Composition dependent metal-semiconductor transition in transparent and conductive La-doped $\mathrm{BaSnO}_{3}$ epitaxial films. Appl Phys Lett, 2012, 101: 153903

18 McLaughlin M, Sakeek HF, Maguire P, et al. Properties of ZnS thin-films prepared by 248-nm pulsed-laser deposition. Appl Phys Lett, 1993, 63: 1865-1867

19 Shen WP, Kwok HS. Crystalline phases of II-VI compound semiconductors grown by pulsed-laser deposition. Appl Phys Lett, 1994, 65: 2162-2164

20 Liu HL, Shi X, Xu FF, et al. Copper ion liquid-like thermoelectrics. Nat Mater, 2012, 11: 422-425

21 Liu HL, Yuan X, Lu P, et al. Ultrahigh thermoelectric performance by electron and phonon critical scattering in $\mathrm{Cu}_{2} \mathrm{Se}_{1-x} \mathrm{I}_{x}$. Adv Mater, 2013, 25: 6607-6612

22 Dean JA. Lange's Handbook of Chemistry (16th edition), Section 4: Properties of Atoms, Radicals, and Bonds. New York: McGraw-Hill, Inc, 2004

23 Schou J. Physical aspects of the pulsed laser deposition technique: the stoichiometric transfer of material from target to film. Appl Surf
Sci, 2009, 255: 5191-5198

24 Aruta C, Amoruso S, Bruzzese R, et al. Pulsed laser deposition of $\mathrm{SrTiO}_{3} / \mathrm{LaGaO}_{3}$ and $\mathrm{SrTiO}_{3} / \mathrm{LaAlO}_{3}$ : plasma plume effects. Appl Phys Lett, 2010, 97: 252105

25 Canulescu S, Papadopoulou EL, Anglos D, et al. Mechanisms of the laser plume expansion during the ablation of $\mathrm{LiMn}_{2} \mathrm{O}_{4}$. J Appl Phys, 2009, 105: 063107

26 Amoruso S, Aruta C, Bruzzese R, et al. Substrate heating influence on the deposition rate of oxides during pulsed laser deposition in ambient gas. Appl Phys Lett, 2011, 98: 101501

27 Amoruso S, Schou J, Lunney JG, Influence of the atomic mass of the background gas on laser ablation plume propagation. Appl Phys A, 2008, 92: 907-911

28 Heiroth S, Ghisleni R, Lippert T, Michlerb J, Wokaun A. Optical and mechanical properties of amorphous and crystalline yttria-stabilized zirconia thin films prepared by pulsed laser deposition. Acta Mater, 2011, 59: 2330-2340

29 Infortuna A, Harvey AS, Gauckler LJ. Microstructures of CGO and YSZ thin films by pulsed laser deposition. Adv Funct Mater, 2008, 18: $127-135$

Acknowledgments This work was supported by the National Basic Research Program of China (2013CB632501), the National Natural Science Foundation of China (51472262), and the Key Research Program of Chinese Academy of Sciences (KGZD-EW-T06).

Author contributions Chen $\mathrm{J}$ and Lv Y designed and performed the experiments. Döbeli M performed the RBS experiments. Chen J wrote the paper. All authors contributed to the general discussion and writing.

Conflict of interest The authors declare that they have no conflict of interest. 


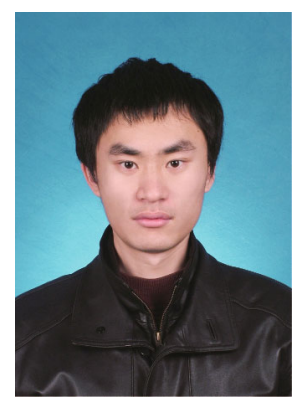

Jikun Chen is a visiting researcher at Shanghai Institute of Ceramics, Chinese Academy of Sciences, and a postdoctoral researcher at the School of Engineering and Applied Sciences, Harvard University. He got his PhD degree from the Department of Chemistry and Applied Biology, ETH Zürich in 2014, MSc degree from the University of Chinese Academy of Sciences in 2011, and BSc degree from the Department of Materials Science and Engineering, Tsinghua University in 2008.

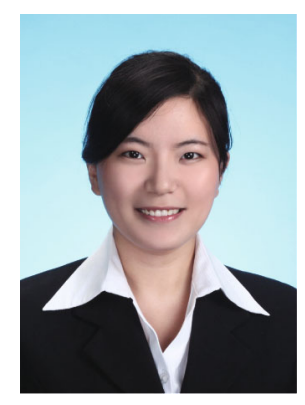

Yanhong $\mathbf{~} \mathbf{v}$ is a PhD candidate at Shanghai Institute of Ceramics, Chinese Academy of Sciences. Her research is focused on the copper chalcogenide thermoelectric films. She received her MSc degree in Materials Engineering from Lanzhou Institute of Chemical Physics, Chinese Academy of Sciences in 2012, and BSc degree from Shandong normal University in 2008.

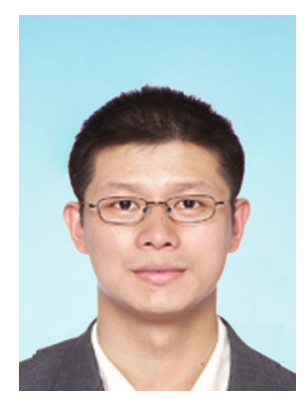

Xun Shi is a professor and the vice director of Energy Materials Research Center at Shanghai Institute of Ceramics, Chinese Academy of Sciences. He received his PhD degree at shanghai institute of Ceramics, Chinese Academy of Sciences in 2005. His current research focuses on electrical and thermal transport, and thermoelectric materials.

中文摘要 本文阐述了在利用脉冲激光沉积法生长亚铜基硫族化合物薄膜过程中, 所使用的氩气背景气体压力与薄膜化学组分的关系. 当氩气压力在 $10^{-2} \mathrm{mbar}$ 时, 薄膜材料中原子量较轻的成分缺失更为严重. 与之相比, 当利用准真空或 $10^{-1} \mathrm{mbar}$ 时薄膜材料化学组分 与所用靶材组分更为接近. 以硒化亚铜为例, 研究结果显示所生长薄膜材料的电输运性能与铜硒组分比例随压力的变化相一致. 当生 长条件为真空或准真空时, 所生长的硒化亚铜薄膜具有致密的结构和最佳的化学组分, 因而具有最优的热电性能. 